University of Nebraska - Lincoln

DigitalCommons@University of Nebraska - Lincoln

US Army Research

U.S. Department of Defense

2000

Development of Vaccines for Prevention of Botulism

Michael P. Byrne

Leonard A. Smith

Follow this and additional works at: https://digitalcommons.unl.edu/usarmyresearch

Part of the Operations Research, Systems Engineering and Industrial Engineering Commons

Byrne, Michael P. and Smith, Leonard A., "Development of Vaccines for Prevention of Botulism" (2000). US Army Research. 15.

https://digitalcommons.unl.edu/usarmyresearch/15

This Article is brought to you for free and open access by the U.S. Department of Defense at DigitalCommons@University of Nebraska - Lincoln. It has been accepted for inclusion in US Army Research by an authorized administrator of DigitalCommons@University of Nebraska - Lincoln. 


\title{
Development of vaccines for prevention of botulism
}

\author{
Michael P. Byrne, Leonard A. Smith* \\ Department of Immunology and Molecular Biology, Division of Toxinology, United States Army Medical Research Institute of \\ Infectious Diseases, 1425 Porter Street, Fort Detrick, MD 21702-5011, USA
}

(Received 12 May 2000; accepted 24 August 2000)

\begin{abstract}
Botulism is a potentially lethal disease caused by one of seven homologous neurotoxic proteins usually produced by the bacterium, Clostridium botulinum. This neuromuscular disorder occurs through an exquisite series of molecular events, ultimately ending with the arrest of acetylcholine release and hence, flaccid paralysis. The development of vaccines that protect against botulism dates back to the 1940s. Currently, a pentavalent vaccine that protects against BoNT serotypes A-E and a separate monovalent vaccine that protects against BoNT serotype F are available as Investigational New Drugs. However, due to the numerous shortcomings associated with the toxoid vaccines, several groups have efforts towards developing next-generation vaccines. Identifying a synthetic peptide that harbors a neutralizing epitope is one approach to a BoNT vaccine, while another employs the use of a Venezuelan equine encephalitis virus replicon vector to produce protective antigens in vivo against BoNT. The strategy used in our laboratory is to design synthetic genes encoding non-toxic, carboxy-terminal fragments of the $C$. botulinum neurotoxins $\left(\mathrm{rBoNT}\left(\mathrm{H}_{\mathrm{C}}\right)\right)$. The gene products are expressed in the yeast, Pichia pastoris, and purified to greater than $98 \%$ with yields typically ranging from $200-500 \mathrm{mg}$ per $\mathrm{kg}$ of wet cells. Protective immunity to the purified products against high-level challenges of neurotoxin is elicited in mice and in non-human primates. A pre-Investigational New Drug meeting was held with the Food and Drug Administration, and the next milestone for the vaccine candidates will be clinical trials. () 2000 Société française de biochimie et biologie moléculaire / Éditions scientifiques et médicales Elsevier SAS
\end{abstract}

\section{botulinum neurotoxin / vaccine / C-fragment / purification / efficacy}

\section{Introduction}

The toxins produced by the bacterium, Clostridium botulinum, are the most lethal substances known and are the causative agents of the disease, botulism. Indeed, a single molecule can abolish the function of a nerve cell, while a lethal dose is on the order of ng per $\mathrm{kg}$ of body weight [1]. The botulinum neurotoxins (BoNT) are produced by one of seven structurally similar $C$. botulinum serotypes, designated A to G. These toxins exert their action by arresting the release of the neurotransmitter, acetylcholine, at the neuromuscular junction [2-4]. Clinical manifestations of the disease are dominated by the neurological signs and symptoms resulting from a toxininduced blockade of the voluntary motor and autonomic cholinergic junctions. Symmetrical cranial nerve impairment affecting the bulbar musculature frequently marks the onset of symptoms such as ptosis, ambiopia and/or blurred vision, dysphonia, and a dry, sore throat. Flaccid paralysis of the pharyngeal and laryngeal muscles gives rise to dysphagia and dysarthria. If botulism is a consequence of ingesting improperly preserved foodstuffs con-

\footnotetext{
* Correspondence and reprints.

E-mail address: leonard.smith@det.amedd.army.mil (Leonard A. Smith).
}

taminated with bacteria and their pre-formed toxins, nausea, abdominal pain, vomiting, and diarrhea may often precede or accompany the neurologic indications. As the disease progresses, a descending paralysis ensues in which the neck muscles, respiratory muscles, and muscles in the extremities and trunk are affected. The paralysis of the respiratory muscles leading to dyspnea or ventilatory failure is the cause of death in a botulinum intoxication.

BoNT are initially synthesized as $150-\mathrm{kDa}$, single polypeptide chain, precursor proteins which are posttranslationally nicked forming a dichain consisting of a C-terminal 100-kDa heavy chain and a N-terminal 50-kDa light chain. The dichain remains covalently attached by a disulfide link $[5,6]$ but the extent of nicking varies from completely nicked (serotype A) to completely non-nicked (serotype E) (figure 1). The mechanism of nerve intoxication is accomplished through the interplay of three key events, each of which is performed by a separate portion of the neurotoxin molecule (see [7-9] for reviews). First, the carboxy half of the heavy chain (fragment $\mathrm{C}$ or $\mathrm{H}_{\mathrm{C}}$ ) is required for receptor specific binding to cholinergic nerve cells [10-12]. There is evidence suggesting that polysialogangliosides [13] or synaptotagmin [14, 15] could act as receptors for the toxins but the data supporting a specific receptor remain equivocal [16]. After binding, the toxin is internalized into an endosome through receptor-mediated 


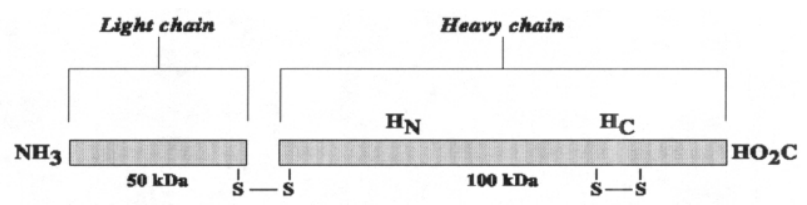

Figure 1. Schematic diagram of BoNT primary structures. Protease nicking site distinguishes the light and heavy chains which remain covalently associated by a disulfide link.

endocyctosis [17, 18]. The amino-terminal half of the heavy chain $\left(\mathrm{H}_{\mathrm{N}}\right)$ is believed to participate in the translocation mechanism of the light chain across the endosomal membrane [4, 19-22]. The low $\mathrm{pH}$ environment of the endosome may trigger a conformational change in the translocation domain, thus forming a channel for the light chain. Alternatively, the receptor may assist the toxin in transporting the light chain across the membrane. The final event of intoxication involves the catalytic hydrolysis of key synaptic vesicle proteins [3, 23-25] by the light chain $[3,26]$. The light chains are zinc-dependent endoproteases that selectively inactivate three essential proteins involved in the docking and fusion of acetylcholinecontaining synaptic vesicles to the plasma membrane. The light chains of BoNT serotypes $A, C_{1}$, and $E$ cleave SNAP-25 (synaptosomal-associated protein of $25 \mathrm{kDa}$ ) [27-30]; serotypes B, D, F, and G cleave VAMP/ synaptobrevin (synaptic vesicle-associated membrane protein) [31]; and serotype $\mathrm{C}_{1}$ cleaves syntaxin [32]. Inactivation of SNAP-25, VAMP, or syntaxin by BoNT leads to an inability of the nerve cells to release acetylcholine, resulting in neuromuscular paralysis.

\section{BoNT toxoid vaccines}

Prophylactic and therapeutic countermeasures to botulism have been investigated since the 1940s. Inhibition of BoNT action at any of the key steps of the process outlined above could abolish the onset of botulism. Currently, a pentavalent botulinum toxoid (PBT), against serotypes A through E [33-36], is used to immunize specific populations of at-risk individuals, i.e., scientists and health care providers who handle BoNT, and our armed forces, who may be subjected to weaponized forms of the toxin.

The manufacture of PBT, by the Michigan Department of Public Health (MDPH), took place in stages and over many years. The fermentation, isolation, purification and detoxification steps for each serotype took place in the late 1960s and early 1970s. The toxoid was manufactured by initially culturing $C$. botulinum serotypes A-E to produce crude preparations of neurotoxins. The toxins were separated from the culture fluid by acid precipitation overnight in the cold, then separated from the supernatant fluid by filtration and/or centrifugation. The precipitated toxin was washed, extracted, and filtered to remove any particulate material. Toxins were again precipitated, filter-sterilized, and detoxified by adding formalin. Residual formalin was left in the vaccine products to ensure that the neurotoxins remained non-toxic. Monovalent vaccines were then adsorbed to aluminum hydroxide and blended into a pentavalent vaccine. The monovalent bulks were completed in 1971, and first packaged in 1978. Investigational New Drug (IND) status was granted for the PBT under the Centers for Disease Control's IND 161 (at risk workers) and under the United States Army's Office of Surgeon General IND 3723 (for military deployment). The MDPH product was studied and used as an investigational vaccine from 1979 until the present time.

An effort is ongoing on the part of the United States Army to obtain Food and Drug Administration (FDA) licensure for the PBT lots PBP003 and PBP004. For licensure of the PBT, FDA required (1) that a pivotal clinical trial be performed to reevaluate safety and assess immunogenicity of the toxoid, and (2) that a new lot of toxoid be manufactured to demonstrate reproducibility and robustness of the manufacturing process, and consistency of the manufactured product. The final report on the pivotal clinical study was expected in June 2000. This study will have evaluated, in a significant number of participants, the protective immunogenicity of all five serotype vaccines with respect to their homologous neurotoxins. Results from this pivotal study and the status of a new-generation, recombinant vaccine will be factors in deciding whether to proceed with a new lot of toxoid.

Though serotypes A, B, and E are most associated with botulism outbreaks in humans, type $\mathrm{F}$ has also been diagnosed [37-39]. A separate monovalent toxoid vaccine against BoNTF [40] was manufactured for the U.S. Army by Porton Products Limited in cooperation with the United Kingdom Governments Center for Applied Microbiology and Research (CAMR) in 1990. The vaccine batch no. 002/90 was derived from pooling three production lots of $C$. botulinum $\mathrm{F}$ toxin. The harvested toxin (i.e., by acid precipitation, tangential flow filtration, and centrifugation) from each of three fermentation runs was pooled, and the type $\mathrm{F}$ toxin extracted with sodium phosphate buffer. After ribonuclease treatment, the toxin was further purified by ammonium sulfate precipitation, and repeated fractionation on fast liquid column chromatography on a fast flow Q Sepharose column. Unlike the toxoid (estimated toxoid purity of 10\%) [36], the purity of the type $\mathrm{F}$ botulinum toxoid Lot no. 002/90 was greater than $60 \%$ (IND 5077). The partially purified $\mathrm{F}$ toxin was formalin-detoxified and adsorbed to aluminum hydroxide.

An IND application was filed with FDA in April 1993 to conduct a phase I clinical trial to evaluate the safety of the botulinum $F$ toxoid vaccine. The clinical study was conducted by the Medical Division at the U.S. Army 
Medical Research Institute of Infectious Diseases under IND 5077. The toxoid was well-tolerated in all of the 35 participants receiving the vaccine. Immunogenicity data gathered on sera from the recipients of the vaccine demonstrated that two doses of vaccine (10 $\mu \mathrm{g}$ per dose) produced an antibody response considered protective by the CDC guidelines (a titer $>0.02 \mathrm{IU} / \mathrm{mL}$ ). Ninety percent $(18 / 20)$ of the volunteers seroconverted after two vaccinations and $100 \%(10 / 10)$ after three vaccinations [41].

A phase II clinical trial was conducted under IND 5077 at the University of Maryland Medical School (Baltimore, MD) over 3 years (1995-1998) in 144 healthy adult volunteers. The phase II trial was conducted to expand the limited Army phase I trial and to identify a vaccination schedule that was safe and maximally immunogenic for volunteers. Administered (10 $\mu \mathrm{g}$ per dose) as a primary series of three injections (i.e., at 0,7 , and 28 days; 0,14 , and 42 days; and 0,21 , and 42 days), and as a booster injection 12 months post primary series (if required), the C. botulinum Type F toxoid was generally well-tolerated and safe whether injected by the subcutaneous or intramuscular route. The $C$. botulinum Type $\mathrm{F}$ toxoid induced significantly more immediate pain on injection than did the licensed hepatitis B vaccine control, although the pain was transient and tolerated (Dr. Robert Edelman, personal communication).

Immunological response indicated that 61 to $83 \%$ of the study subjects met the criteria for a booster dose at 1 year because of their low antitoxin levels (i.e., $<0.10$ $\mathrm{IU} / \mathrm{mL}$ ) at 6 months. One hundred percent of the subjects boosted at 1 year developed high concentrations of protective antitoxin by day 56 post-boost, and protective levels $(\geq 0.02 \mathrm{IU} / \mathrm{mL})$ persisted for at least 360 days in all subjects (Dr. Robert Edelman, personal communication).

Even though toxoid vaccines are available, there are numerous shortcomings with their current use and ease of production. First, because $C$. botulinum is a spore-former, a dedicated facility is required to manufacture a toxinbased product. The requirement for a dedicated manufacturing facility is not trivial. It is extremely costly to renovate and upgrade an existing facility or to build a new one and then to maintain the facility in accordance with current Good Manufacturing Practices (cGMP) to manufacture one vaccine. Second, the yields of toxin production from $C$. botulinum are relatively low. Third, the toxoiding process involves handling large quantities of toxin and thus is dangerous, and the added safety precautions increase the cost of manufacturing. Fourth, the toxoid product for types A-E consists of a crude extract of clostridial proteins that may influence immunogenicity or reactivity of the vaccine, and the type $\mathrm{F}$ toxoid is only partially purified (IND 5077). Fifth, because the toxoiding process involves the use of formaldehyde, which inactivates the toxin, and residual levels of formaldehyde (not to exceed $0.02 \%$ ) are part of the product formulation to prevent reactivation of the toxin, the vaccine is reactoge- nic. An additional component of the toxoid vaccines is the preservative thimerosal $(0.01 \%)$, which also increases the reactogenicity of the product.

The development of a new-generation, recombinant vaccine could alleviate many of the problems associated with the toxoid. A recombinant vaccine would eliminate the need for a dedicated manufacturing facility. Presently, many cGMP facilities are in existence and available that could manufacture a recombinant product. There would be no need to culture large quantities of a hazardous toxinproducing bacterium. Production yields from a genetically engineered product is expected to be high. Presumably, there would be no need to treat the vaccine with formalin if the recombinant vaccine candidate represented a fragment of the toxin. A fragment would not possess all three functional domains (i.e., binding, internalization, catalytic) which are all required for its mechanism of action. Recombinant products would be purer, less reactogenic, and more fully characterized. Thus, the cost of a recombinant product would be expected to be much lower than a toxoid because there would be no expenditures required to support a dedicated facility, and the higher production yields would reduce the cost of the vaccine product.

\section{Other strategies for developing a BoNT vaccine}

There are alternative approaches to developing vaccines against the botulinum neurotoxins that are currently being pursued by several laboratories. We summarize two of those strategies below.

The efforts in the laboratory of Atassi and coworkers have focused on the development of a synthetic vaccine against BoNT intoxication [42, 43]. The investigators synthesized a series of overlapping 19-mer peptides that spanned the entire $\mathrm{H}_{\mathrm{C}}$ region of BoNT serotype A (BoNT/ A). These peptides were thoroughly analyzed for their ability to be recognized by anti-BoNT/A antibodies raised in human, horse, and mouse. In addition to mapping the epitopes using antibodies, the epitopes were mapped using T-lymphocytes as well. The investigators have identified which peptides elicit antibody and T-cell responses in two different strains of mice (BALB/c and SJL) that crossreact with the $\mathrm{H}_{\mathrm{C}}$ region of BoNT/A. These experiments provide the foundation for possibly developing a synthetic vaccine that could protect against botulinum neurotoxin intoxication.

Venezuelan equine encephalitis (VEE) virus replicon vectors have emerged as an effective strategy for developing candidate vaccines. Pushko et al. have demonstrated that when a heterologous gene encoding influenza hemagglutanin (HA) or the Lassa virus nucleocapsid (N) is substituted for the VEE structural proteins followed by transfection into eukaryotic cells, the replicon system can express high levels of HA or N proteins [44]. When packaged into virus-like particles, these replicons have 
also been found to induce potent immune responses in inoculated animals against the heterologous proteins, and to protect animals against challenge with the heterologous virus. Similarly, Lee and coworkers introduced the gene fragment encoding the nontoxic $\mathrm{H}_{\mathrm{C}}$ region of BoNTA into the VEE virus replicon vector. This construct not only yielded high levels of $\mathrm{H}_{\mathrm{C}}$ in BHK cells as judged by immunofluorescence and Western analysis, but also protected mice against a $10^{5} \mathrm{LD}_{50}$ challenge of BoNTA (Lee J.S., Pushko P., Parker M.D., Dertzbaugh M.T., Smith L.A., Smith J.F., in preparation).

\section{Recombinant vaccines against BoNT}

In 1984, Helting and Nau [45] demonstrated that protein fragments generated from papain-digested tetanus toxin (TeNT) elicited protective immunity in mice. A few years later, Fairweather and coworkers [46] showed that partially purified recombinant fragment $\mathrm{C}$ from tetanus toxin $\left(\mathrm{rTeNT}\left(\mathrm{H}_{\mathrm{C}}\right)\right)$ protected mice when challenged with $10 \mathrm{LD}_{50}$ of tetanus toxin. Because of the high sequence and structural homology that exists between the clostridial neurotoxins produced by $C$. tetani and $C$. botulinum, we applied this strategy to developing a vaccine to protect against botulism.

We demonstrated early on that we could subclone segments of the BoNTA gene and express these non-toxic fragments in Escherichia coli [47]. We were then able to vaccinate mice with the non-toxic recombinants and test their ability to elicit protective immunity in vivo. Clones pCBA2, pCBA3, and pCBA4 (gift from Nigel Minton) containing overlapping gene fragments of the BoNTA gene [48], were the source for templates used to produce the various antigens to be examined. Smaller versions of the gene fragments were constructed by cutting with restriction enzymes. Specific gene segments were produced by PCR. Expressed products were identified by SDS-PAGE and Western blot analyses, partially purified, and used to vaccinate mice. Antigens representing various regions from the three functional domains of the toxin were analyzed for their ability to elicit protective antibodies in mice. Of all the fragments we and others [49-51] tested, only one was able to completely protect mice. This was the fragment located at the carboxy-terminus of the toxin $(\sim 50 \mathrm{kDa})$ designated as the fragment $\mathrm{C}$ region. Our subsequent efforts to develop vaccine candidates to protect against BoNT forthwith focused exclusively on the $\mathrm{H}_{\mathrm{C}}$ region.

One could imagine the most ideal recombinant BoNT vaccine candidate would be the smallest, non-toxic fragment of the toxin capable of eliciting significant protective immunity, while being completely devoid of any detectable biological property associated with its parent neurotoxin (i.e., receptor binding, translocation, and/or en- doproteolytic activity). One approach to a recombinant BoNT vaccine has been proposed [52] which would employ a mutated holotoxin as the immunogen. In this appraoch, the endoproteolytic activity of the light chain would be removed by altering the amino acid residues required for zinc binding $\left(\mathrm{H}^{229} \rightarrow \mathrm{G}\right.$ and $\left.\mathrm{H}^{233} \rightarrow \mathrm{N}\right)$ and the water molecule binding $\left(\mathrm{E}^{230} \rightarrow \mathrm{T}\right)$ [52]. The resultant immunogen, however, would still retain binding and internalization activities. We believed the retention of those activities could be problematic in terms of their effects on safety and the additional testing we might be required to do to convince the Center for Biologics Evaluation and Review (CBER) at FDA that this product was safe. And indeed, at a pre-IND meeting on April 9, 1999 , held to review the recombinant $\operatorname{BoNT}\left(\mathrm{H}_{\mathrm{C}}\right)$ vaccines, a CBER panel voiced concern as to the potential of our putative $\mathrm{H}_{\mathrm{C}}$ vaccine to cause adverse neurological reactions or disorders due to its nature of binding to specific receptors on cholinergic nerve cells. Although in competition studies, BoNTA- and $\mathrm{B}\left(\mathrm{H}_{\mathrm{C}}\right)$ vaccines did not compete with the neurotoxin for receptor binding (unpublished data), the CBER panel recommended we do additional testing (e.g., Functional Observational Battery [53, 54] beyond the acute toxicology testing already performed on these vaccine candidates).

\section{Design of synthetic BoNT $\left(\mathrm{H}_{\mathrm{C}}\right)$ gene, construct, and expression in Pichia pastoris}

The yeast strain Pichia pastoris, originally developed by the Phillips Petroleum Company, was chosen as a host because of the high level of recombinant expression exhibited by this system with other proteins [55-58]. Clare and coworkers [59] reported yields of $12 \mathrm{~g} / \mathrm{L}$ of TeNT $\left(\mathrm{H}_{\mathrm{C}}\right)$ when expressed in $P$. pastoris. Using $P$. pastoris would also eliminate the potential problems associated with inclusion bodies formed during expression in $E$. coli, as well as the need to remove endotoxin.

Because of rare codons [60], and high adenine and thymine (A+T)-rich base compositions [61] found in the naturally-occuring clostridial DNA, it was necessary to construct synthetic genes $[57,59,61]$ to eliminate these impediments to optimal expression in heterologous expression systems such as E. coli and yeast. We prepared synthetic genes for the $\mathrm{H}_{\mathrm{C}}$ of BoNT with codon usage specified by highly expressed genes in $E$. coli and yeast. Genes designed and constructed using $E$. coli codon usage [62] expressed full-length products in both $E$. coli and $P$. pastoris, while genes designed and constructed using $P$. pastoris codon usage [63] likewise, expressed proteins with the expected molecular mass in both hosts.

In designing the length of the $\mathrm{BoNT}\left(\mathrm{H}_{\mathrm{C}}\right)$ genes, there was a question as to where the $\mathrm{H}_{\mathrm{C}}$ region of BoNT began, because unlike TeNT, BoNTs do not possess a unique papain cleavage site. It was critical that the expressed 
product properly fold into a conformation that would not disrupt the neutralizing epitope(s). Also, if the $\mathrm{H}_{\mathrm{C}}$ folded properly, the chance of expressing a soluble antigen would increase. We believed the best strategy for meeting those requirements would occur if the gene encoded a homologous region in $\operatorname{BoNT}\left(\mathrm{H}_{\mathrm{C}}\right)$. Also, the crystal structures for the TeNT binding domain [64] and the BoNTA [65] were not available until 1997, thus deciding where the recombinant vaccine should begin was suggested by using sequence alignments and theoretical secondary structural analyses. The published three-dimensional structure of BoNTA revealed that the topology of the $\mathrm{H}_{\mathrm{C}}$ was defined by two sub-domains, an N-terminal jelly roll motif and a $\mathrm{C}$-terminal modified $\beta$-trefoil domain. There exists substantial sequence homology among the fragment $\mathrm{C}$ serotypes; however, sequence alignment of the final approximately 150 residues of the $\beta$-trefoil significantly deviates from the homology [66]. Because there is very little cross-reactivity among the serotypes, there is conjecture that the final approximately 150 residues of the $\mathrm{H}_{\mathrm{C}}$ possess the protective epitope(s) [67].

Synthetic genes encoding BoNT- $\mathrm{A}\left(\mathrm{H}_{\mathrm{C}}\right), \mathrm{B}\left(\mathrm{H}_{\mathrm{C}}\right)$, and $\mathrm{E}$ $\left(\mathrm{H}_{\mathrm{C}}\right)$, were initially inserted into the yeast secretion vector, pPIC9K [68] and fused to the $\alpha$-mating factor signal sequence for secretion from the yeast cell into the medium. There are many heterologous proteins secreted from yeast and this approach offered certain advantages over intracellular expression, including the production of a purer protein fraction with which to begin process development. However, secretion of $\mathrm{H}_{\mathrm{C}}$ proteins resulted in the unwanted glycosylation of expressed products [47]. Therefore, the gene was placed in a vector that would allow the product to be expressed intracellularly.

The synthetic genes were subsequently inserted into the yeast expression vector, pHILD4 (for description see [69]) for intracellular expression. The expression cassette was integrated into the chromosomal alcohol oxidase of $P$. pastoris strain GS115 [59]. Yeast transformants expressing the selectable markers, histidine dehydrogenase [70] and aminoglycoside phosphotransferase 3' I [68], were isolated. Clones were assessed by their ability to express recombinant proteins with expected molecular masses as judged by SDS-PAGE and Western blot analysis. Positive clones were selected for growth in a fermentation reactor under the control of methanol induction. The fermentation process consisted of three phases: a batch phase where pichia cells grew exclusively on glycerol, followed by a fed-batch phase of decreasing glycerol, and finally a fed-batch phase of increasing methanol. Typically, the methanol induction phase was 10-70 $\mathrm{h}$ depending on the antigen, yielding a final cell mass of approximately $60 \mathrm{~g}$ dry cell weight per liter of fermentation broth. Fermentation conditions have been worked out for optimum yield of $\mathrm{H}_{\mathrm{C}}$ for each of the serotypes $[69,71,72]$.

\section{Process for purifying $\operatorname{BoNT}\left(\mathrm{H}_{\mathrm{C}}\right)$ from Pichia pastoris}

At the time of this review, a bioprocess development was completed for BoNT $\left(\mathrm{H}_{\mathrm{C}}\right)$ serotypes $\mathrm{A}, \mathrm{B}, \mathrm{C}_{1}$, and $\mathrm{F}$ [69, 71-74] (Smith L.A., Byrne M.P., in preparation) and a manufacturing process for serotype $\mathrm{E}$ is in development. Purification streams for the vaccines are briefly discussed below and outlined in figure 2. Because the ultimate objective of this work is to produce a vaccine product suitable for human use (i.e., highly-purified, safe, and effective), our general purification strategy was to employ conventional chromatographic techniques. Even though separations may be accomplished at extremely high resolution with affinity chemistry, there remains an undesirable affect of hapten leaching from the resin. Therefore, an extra step would be required to demonstrate that the product is free of ligand. Furthermore, conventional chromatographic resins are more conducive for scale-up pilot plant separations. As C-fragments lack catalytic activity and any distinguishing chromaphores, purity and identity of the $\mathrm{H}_{\mathrm{C}}$ throughout the process development were monitored by SDS-PAGE and immunological (Western blot and ELISA) detection methods.

Yeast cells were disrupted by using either a Gaulin homogenizer or a microfluidizer device. With either technique, $>95 \%$ cell disruption was achieved as judged by microscopy. The detergent, CHAPS, was incorporated into the cracking buffers for serotypes $\mathrm{A}$ and $\mathrm{C}_{1}$ to facilitate greater yield of product in the soluble fraction. After cell disruption, it was critical that nucleic acids be effectively removed from the soluble extract as they not only interact strongly with BoNT $\left(\mathrm{H}_{\mathrm{C}}\right)$ (types $\mathrm{A}, \mathrm{E}$, and $\mathrm{F}$ ) but also saturate anion-exchange media (as is used in the first step of the type $\mathrm{C}_{1}$ process). The nucleic acids were typically removed by polyethylenimine (PEI) precipitation and/or by diafiltering the soluble extract. For each serotype the initial separation technique was cation-exchange chromatography with only type $\mathrm{C}_{1}\left(\mathrm{H}_{\mathrm{C}}\right)$ requiring anion-exchange chromatography due to its low calculated isoelectric point (pI) (5.3). Except for $\mathrm{B}\left(\mathrm{H}_{\mathrm{C}}\right)$, the final polishing step was hydrophobic interaction chromatography. The process for type B employed a weak anion-exchange step to remove the final impurities. Because of its neutral calculated pI (7.1), type B was amenable to both anion and cation chemistries without subjecting the antigen to extremes of $\mathrm{pH}$. The general use of ion-exchange and hydrophobic interaction chromatographies was an effective strategy because they provide separations based on complimentary physical properties (i.e., electrostatic and hydrophobic interactions). The resulting $\mathrm{H}_{\mathrm{C}}$ products were judged to be $>98 \%$ pure as detected by SDS-PAGE and their yields were generally $200-500 \mathrm{mg} / \mathrm{kg}$ of cells wet weight. A typical cell yield (i.e., wet cell weight) from a 30-L biorector was $6 \mathrm{~kg}$ of wet cell mass. Currently, the type $\mathrm{E}\left(\mathrm{H}_{\mathrm{C}}\right)$ purification process is being developed. A cation- 
A

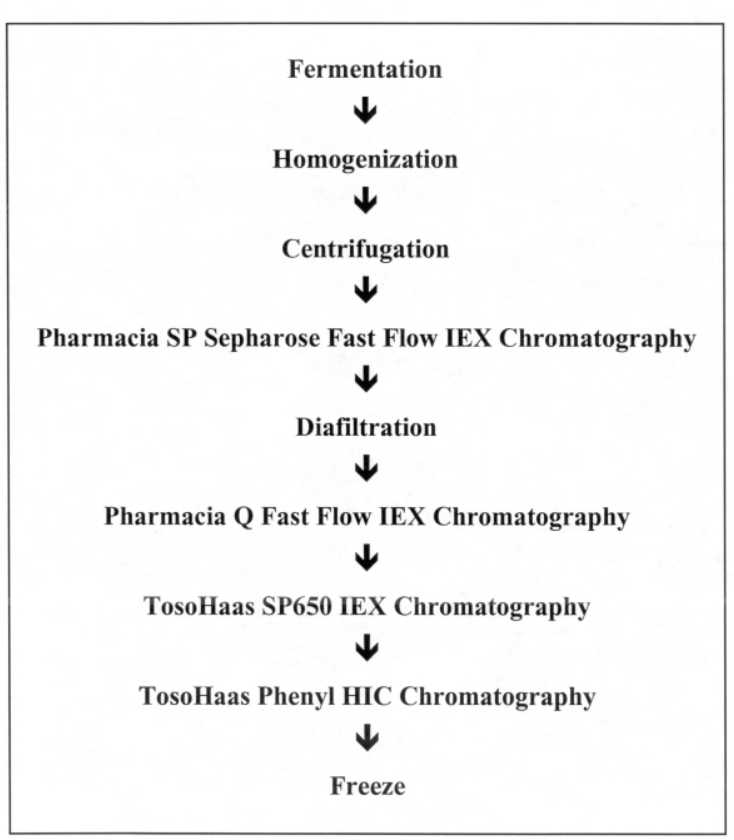

B

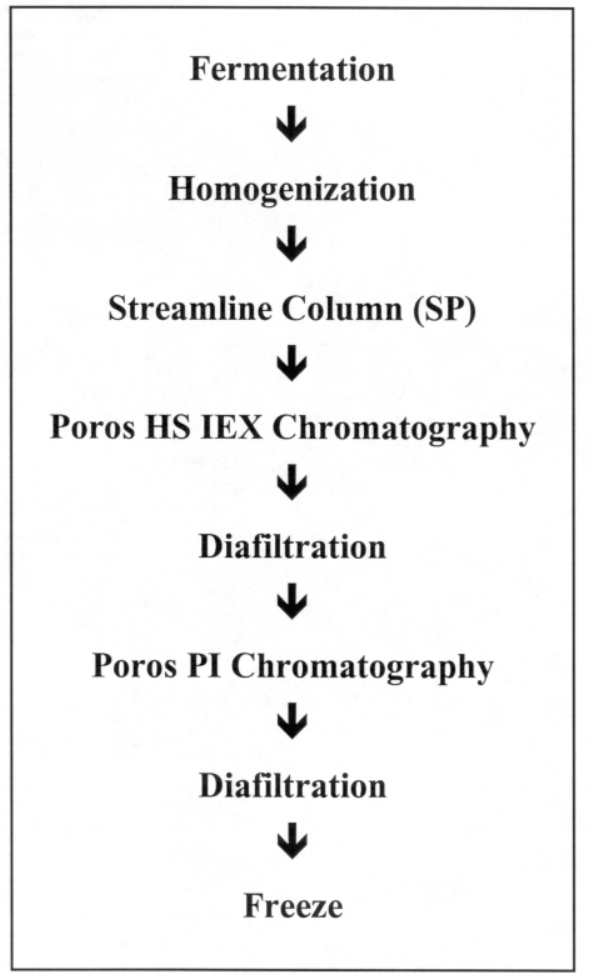

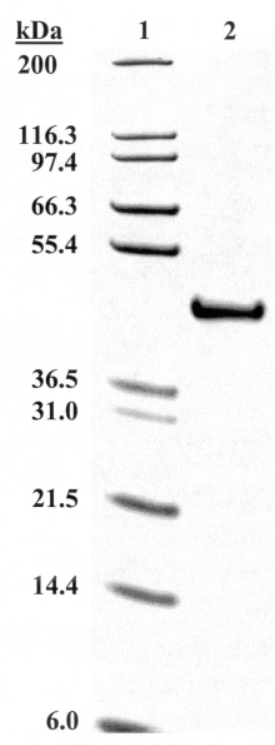

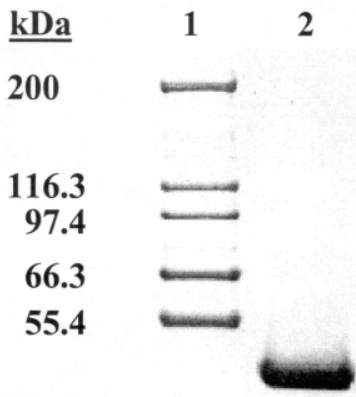

36.5

31.0

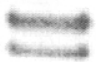

21.5

14.4

6.0

3.5

Figure 2. Production and purification processes for BoNT $\left(\mathrm{H}_{\mathrm{C}}\right)$ serotypes $\mathrm{A}(\mathbf{A}), \mathrm{B}(\mathbf{B}), \mathrm{C}_{1}(\mathbf{C})$, and $\mathrm{F}(\mathbf{D})$ from Pichia pastoris are shown on the left of each panel. SDS-PAGE of purified BoNT $\left(\mathrm{H}_{\mathrm{C}}\right)$ serotypes $\mathrm{A}, \mathrm{B}, \mathrm{C}_{1}$, and $\mathrm{F}$ are shown on the right of each panel. Lane 1 shows the Novex (San Diego, CA, USA) protein standards. 
C
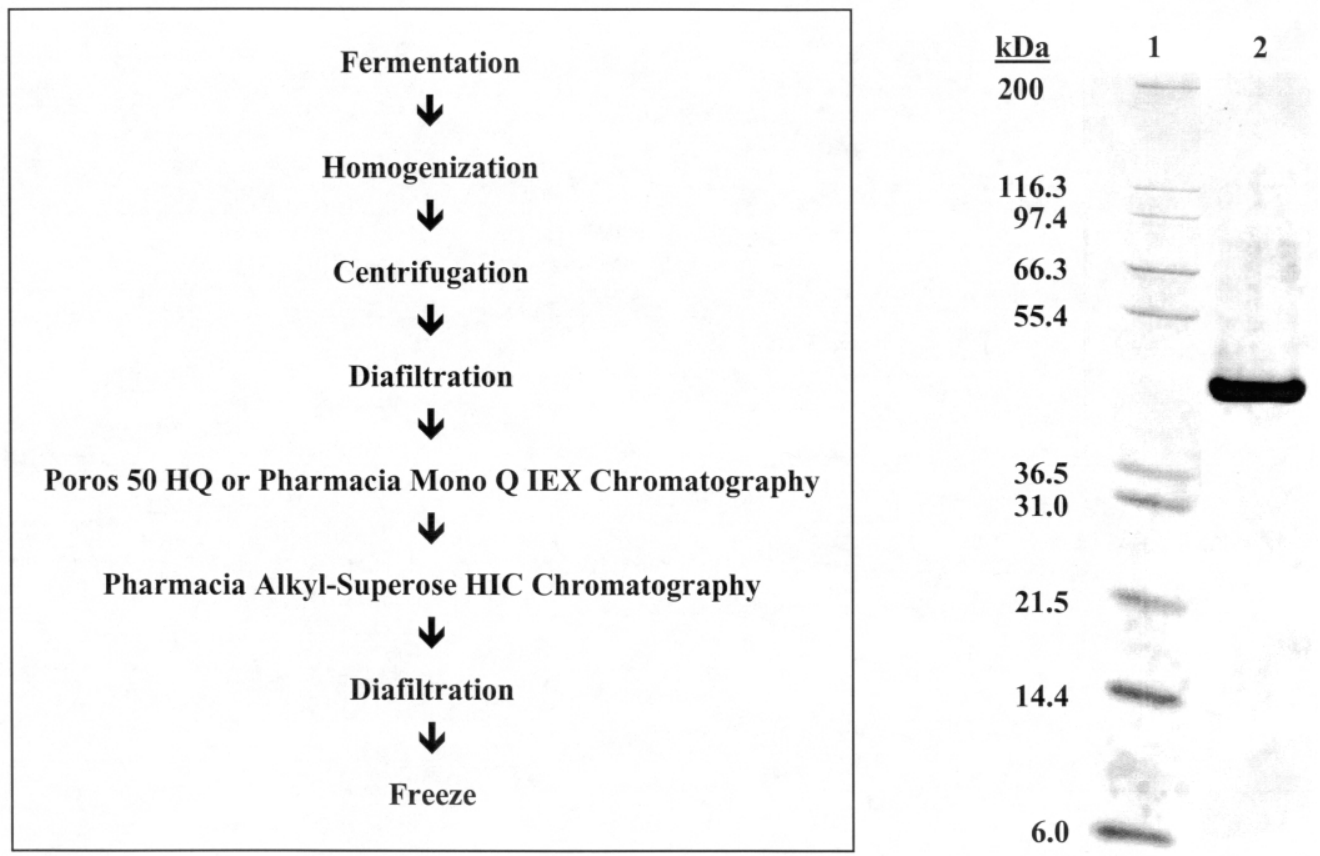

D
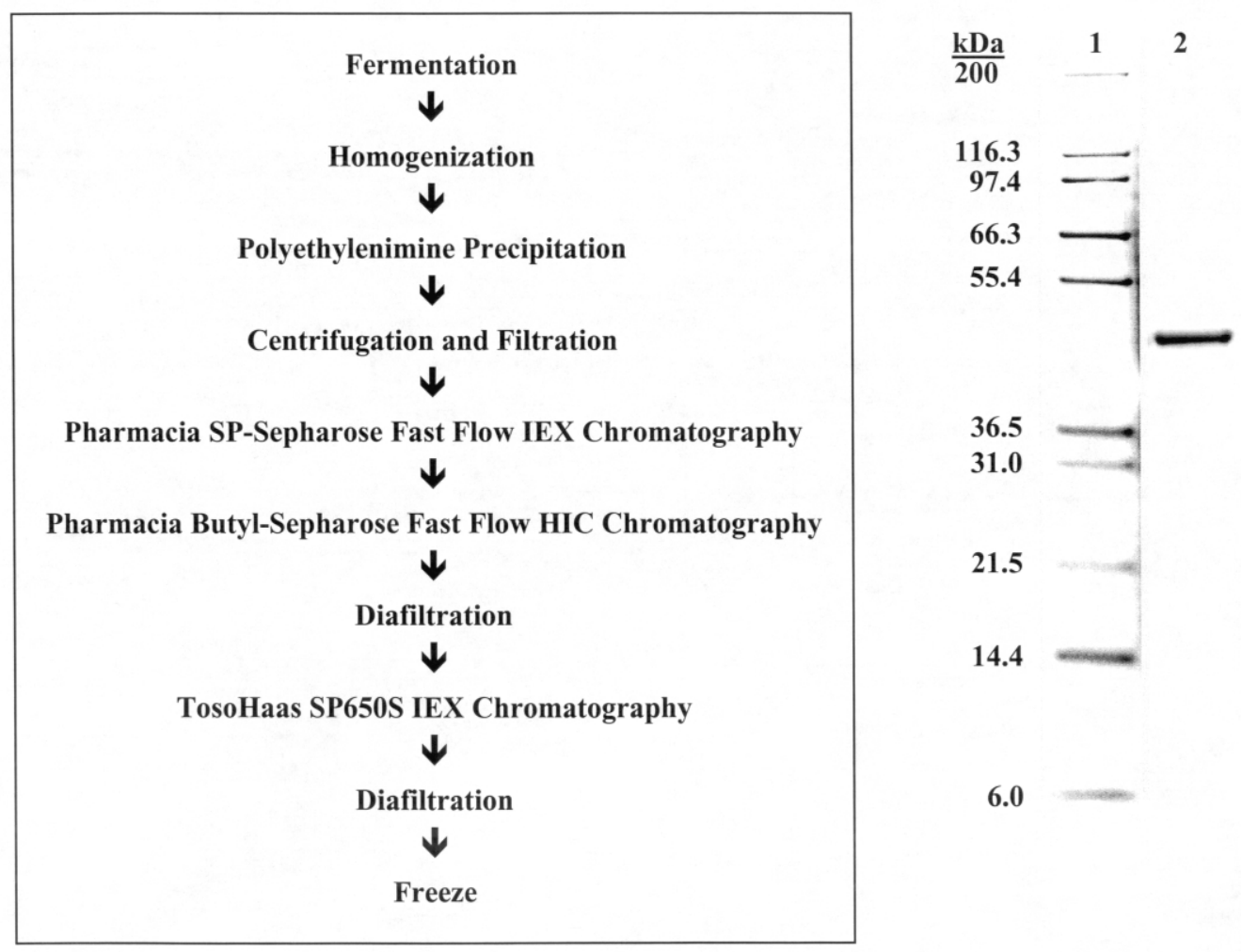

Figure 2. Continued. 
exchange separation will probably be incorporated as the initial chromatography step while subsequent separation techniques are yet to be determined. Yeast clones harboring the fragment $\mathrm{C}$ genes for the last two serotypes (i.e., $\operatorname{rBoNTD}\left(\mathrm{H}_{\mathrm{C}}\right)$ and $\operatorname{rBoNTG}\left(\mathrm{H}_{\mathrm{C}}\right)$ ) have been isolated and process development will begin after completion of $\mathrm{rBoN}$ $\mathrm{TE}\left(\mathrm{H}_{\mathrm{C}}\right)$.

\section{Potency, efficacy, and ELISA of $\operatorname{BoNT}\left(\mathrm{H}_{\mathrm{C}}\right)$}

With any vaccine, the most important question is, how safe and efficacious is the product? In our laboratory and others, many studies have been performed addressing this question, primarily using mice as the animal model, but studies have been performed in non-human primates as well [75]. In general, the $\operatorname{BoNT}\left(\mathrm{H}_{\mathrm{C}}\right)$ are remarkably efficacious antigens. For example, mice vaccinated with as little as $1 \mu \mathrm{g}$ of $\mathrm{B}\left(\mathrm{H}_{\mathrm{C}}\right)$ were fully protected when challenged with as much as $10^{6}$ mouse $\mathrm{LD}_{50}$ of BoNTB [47]. Mice vaccinated with three doses of vaccine remain protected against a challenge of $10^{6}$ mouse $\mathrm{LD}_{50}$ of BoNTB 12 months post-vaccination. Similar long-term protection was also observed in mice for the A serotype vaccine (unpublished data).

One of the most important analyses of a drug product is a potency test. Potency is the specific ability or capacity of the product, as indicated by appropriate laboratory tests or by adequately controlled clinical data obtained through the administration of the product in the manner intended, to affect the given result. The potency assay should be relevant to its intended use, which for a vaccine, is the ability to elicit protective immunity against disease. Our potency assay (Hinz M.E., Smith T.J., Smith, L.A., submitted) involved the administration of an aluminum hydroxide ( $0.2 \%$ Alhydrogel)-adsorbed vaccine to seven groups of mice (10 mice/group for statistical relevance), at doses varying from sub-microgram $(0.011 \mu \mathrm{g})$ to microgram $(8.1 \mu \mathrm{g})$ amounts, in a single intramuscular (i.m.) injection. Three weeks post vaccination, the mice were actively challenged with $10^{3}$ mouse $\mathrm{LD}_{50}$ of neurotoxin by intraperitoneal (i.p.) injection. Figure 3 summarizes the potency results for $\mathrm{H}_{\mathrm{C}}$ serotypes $\mathrm{A}, \mathrm{B}, \mathrm{C}_{1}$, and $\mathrm{F}$. Each antigen yielded a dose-response curve liberating $\mathrm{ED}_{50}$ values ranging from $0.089-0.25 \mu \mathrm{g} /$ mouse. Full protection was realized at a single vaccine dose of $2 \mu \mathrm{g} /$ mouse with each serotype except $\mathrm{F}$, where 9 out of 10 survived a $10^{3}$ mouse $\mathrm{LD}_{50}$ toxin challenge.

An efficacy study provides a thorough analysis of the protective effectiveness of an antigen and can be performed in a variety of manners. Antigen dose amount, number of vaccinations, and challenge levels are the three primary parameters that can be investigated individually in an efficacy study. Generally, any two of these parameters can vary in a given study. For example, animals can be offered a range of antigen doses and then chal-

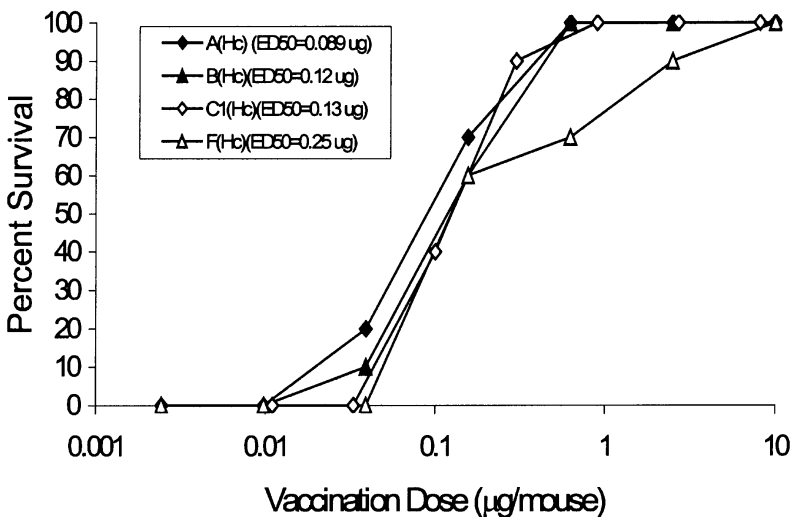

Figure 3. Dependence of mouse survival on a single dose of purified $\mathrm{H}_{\mathrm{C}}$. Mice (Cr1:CD-1(ICR)) were challenged with $10^{3}$ i.p. $\mathrm{LD}_{50}$ of BoNT toxin 21 days after vaccination.

lenged with increasing amounts of toxin (e.g., $10^{3}, 10^{4}$, and $10^{5} \mathrm{LD}_{50}$ ), keeping the number of vaccinations constant. Our procedure usually varied antigen dose amount and number of vaccinations while subjecting the animals to a constant high level challenge. Protective efficacy results for $\mathrm{H}_{\mathrm{C}}$ serotypes $\mathrm{A}$ and $\mathrm{B}$ are presented in table I. Clearly, the data reveal that protection increases with increasing number of vaccinations. With three vaccinations of only $0.1 \mu \mathrm{g}, 9$ out of 10 mice (serotype A) and 12 out of 12 mice (serotype B) survived a challenge of $10^{5}$ $\mathrm{LD}_{50}$ of toxin. Standardized efficacy protocols to provide information on short and long-term immunity elicited by the $\mathrm{C}_{1}\left(\mathrm{H}_{\mathrm{C}}\right)$ and $\mathrm{F}\left(\mathrm{H}_{\mathrm{C}}\right)$ vaccines are currently in progress.

Human vaccine efficacy is normally addressed by performing clinical trials in locations where the incidence of disease is predictable and is sufficient to measure a statistically significant reduction in the number of cases of

Table I. Efficacy of $\mathrm{rBoNT}\left(\mathrm{H}_{\mathrm{C}}\right)$ vaccines

\begin{tabular}{lrrrrrr}
\hline & \multicolumn{3}{c}{$\%$ survival $^{a} A\left(H_{C}\right)$} & \multicolumn{3}{c}{$\%$ survival $^{b} B\left(H_{C}\right)$} \\
Vaccination & Number of vaccinations & \multicolumn{3}{c}{ Number of vaccinations } \\
dose $(\mu g)$ & $1 X$ & $2 X$ & $3 X$ & $1 X$ & $2 X$ & $3 X$ \\
\hline 0.01 & 0 & 60 & 50 & 0 & 17 & 58 \\
0.1 & 20 & 50 & 90 & 33 & 83 & 100 \\
0.5 & 40 & 90 & 100 & ND & ND & ND \\
1.0 & 70 & 100 & 100 & 67 & 100 & 100 \\
2.0 & 80 & 100 & 100 & ND & ND & ND \\
5.0 & ND $^{\text {c }}$ & ND & ND & 100 & 100 & 100 \\
\hline
\end{tabular}

a Each group consisted of 10 mice (Cr1:CD-1(ICR)) which were all challenged with $10^{5}$ mouse $\mathrm{LD}_{50}$ BoNTA. ${ }^{\mathrm{b}}$ Each group consisted of 12 mice (Cr1:CD-1(ICR)) which were all challenged with $10^{5}$ mouse $\mathrm{LD}_{50}$ BoNTB. ${ }^{\mathrm{c}} \mathrm{ND}$, value not determined. 
Table II. Antibody ELISA titers and serum neutralization titers of mice after vaccination with $\mathrm{rBoNT}\left(\mathrm{H}_{\mathrm{C}}\right)$.

\begin{tabular}{|c|c|c|c|c|c|c|c|c|c|c|c|c|}
\hline \multirow{3}{*}{$\begin{array}{l}\text { Vaccination } \\
\text { dose }(\mu g)\end{array}$} & \multicolumn{6}{|c|}{ BoNT serotype $A\left(H_{C}\right)$} & \multicolumn{6}{|c|}{ BoNT serotype $B\left(H_{C}\right)$} \\
\hline & \multicolumn{3}{|c|}{$\begin{array}{l}\text { Antibody ELISA titers }{ }^{a} \\
\text { No. vaccinations }\end{array}$} & \multicolumn{3}{|c|}{$\begin{array}{c}\text { Serum neutralization titers } \\
\text { No. vaccinations }\end{array}$} & \multicolumn{3}{|c|}{$\begin{array}{l}\text { Antibody ELISA titers }{ }^{a} \\
\text { No. vaccinations }\end{array}$} & \multicolumn{3}{|c|}{$\begin{array}{c}\text { Serum neutralization titers } \\
\text { No. vaccinations }\end{array}$} \\
\hline & $1 X$ & $2 X$ & $3 X$ & $1 X$ & $2 X$ & $3 X$ & $1 X$ & $2 X$ & $3 X$ & $1 X$ & $2 X$ & $3 X$ \\
\hline 1 & 400 & 18 & 1600 & $<0.16$ & $<$ & 0.49 & 100 & 1 & 25600 & $<$ & $<0$ & 0.76 \\
\hline & 40 & & & & & & 1600 & 25600 & 100 & & & 4.23 \\
\hline 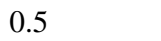 & 400 & 6400 & 25600 & $<0.21$ & 1. & 13. & ND & ND & ND & ND & ND & ND \\
\hline 1.0 & 1600 & 6400 & 25600 & $<0.16$ & 1. & 33. & 6400 & 25600 & 100000 & 0.48 & 1.52 & 13.66 \\
\hline 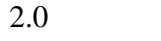 & 16 & 25600 & 1024 & $<0$ & 13. & 33. & ND & $\mathrm{N}$ & ND & $\mathrm{N}$ & $\mathrm{N}$ & ND \\
\hline 5.0 & $\mathrm{ND}^{\mathrm{c}}$ & ND & ND & ND & ND & ND & 25600 & 100000 & 100000 & 0.99 & 3.69 & 12.50 \\
\hline
\end{tabular}

${ }^{\text {a }}$ Pooled mouse serum $(50 \mu \mathrm{L}$ per mouse) from each group was initially diluted 1:100, then four-fold for serum ELISA titers. Titer is reciprocal of the highest dilution having an $\mathrm{OD}_{405}$ greater than $0.2 \mathrm{AU}$ after correcting for background. ${ }^{\mathrm{b}}$ Pooled mouse serum $(50 \mu \mathrm{L}$ per mouse) from each group was initially diluted 1:8, then four-fold for serum neutralization titers in units of IU/mL. ${ }^{\mathrm{c}} \mathrm{ND}$, value not determined.

disease. However, the limited and unpredictable appearance of botulism cases does not allow for the identification of a candidate study population to evaluate the efficacy of a BoNT vaccine by any route of exposure. There is no possibility of a clinical trial where controlled challenge studies could be conducted with a lethal substance in an ethical manner. The ethical and practical obstacles to obtaining direct evidence of human efficacy of a BoNT vaccine led to the development of a human correlate of clinical efficacy for the PBT. Indeed, an FDA advisory panel, in addressing efficacy issues for bacterial vaccines and toxoids, made the following statement (Federal Register, 1985): "For diseases in which immunity depends upon specific antibodies which either neutralize toxin or which opsonize bacteria and lead to their prompt destruction within phagocytes, induction of such antibodies correlates well with protection, and the measurement of such antibodies may reflect efficacy quite faithfully."

For a BoNT vaccine, it is necessary that a correlation be made between the antibodies elicited by the vaccine and their ability to neutralize active toxin. This is accomplished by taking serial dilutions of sera from vaccinated animals, mixing the sera with a constant amount of toxin, and injecting the mixture back into other animals (e.g., mice). The amount of neutralizing antibodies can be determined by the survival rate of the animals used in the test. By definition, 1 international unit (IU) of antitoxin neutralizes $10^{4}$ mouse i.p. $\mathrm{LD}_{50}$ of toxin. There are variations to this neutralization assay that can be more tedious but more indicative of protective efficacy. After antibodies are purified from the sera of vaccinated animals and assayed, they are administered passively to other animals, those animals are then challenged with a known quantity of active toxin by a specified route of delivery (e.g., by aerosol), and the survival rate observed.

We routinely performed mouse neutralization assays on serum samples derived from the recombinant BoNT vaccine efficacy studies to show the correlation between antibody production and toxin neutralization (table II). Additionally, we have assay development studies ongoing to determine the correlation between an immunological response detected by an ELISA (enzyme-linked immunosorbent assay) compared to the mouse neutralization assay. An ELISA is, in most cases, an effective and suitable means to analyze immunological responses to antigens. We have developed a host of ELISAs aimed at detecting BoNT and BoNT fragments for determining serum and neutralization titers of vaccinated animals, for identifying which purification fractions contain product, and for measuring product at various stages of a purification process. Perhaps the greatest benefit an ELISA can provide though, is the reduced use of animals during product development and evaluation. If there exists a high correlation between protection and serum titer, then titers can be used as an alternative to actively challenging mice with toxin. Serum ELISA titers measure the total antibody response to a given antigen, but does not measure the antibodies responsible for neutralizing the toxin.

Table II summarizes the serum ELISA titers and serum neutralizing antibody results of the same mice that were used in the efficacy study described above for $\mathrm{H}_{\mathrm{C}}$ serotypes A and B. The data depicted in table II represents pooled serum from each animal within the group. Though a strong correlation is observed between survival and group ELISA titer data, a significantly higher correlation between survival and individual serum ELISA titers exists. For serotype $\mathrm{A}\left(\mathrm{H}_{\mathrm{C}}\right), 82$ out of 83 mice with titers $\geq 1600$ [73] survived toxin challenge and similarly for serotype $\mathrm{F}\left(\mathrm{H}_{\mathrm{C}}\right)$, all 34 mice with titers $\geq 100$ [69] survived toxin challenge.

\section{Regulatory issues and requirements}

The time and cost in developing prophylactic and therapeutic drugs destined for human use are substantial. 
For this reason, it is critical to know and understand the guidance documents and regulatory issues put forth from one's regulatory agency early in the discovery phase of the product. Title 21 of U.S. Code of Federal Regulations ('21 CFR') states the purpose of GMPs is "to assure that all pharmaceutical, biologic, diagnostic, and medical device products meet all of the requirements of the Federal Food, Drug, and Cosmetic Act as to safety, and efficacy and have the identity and strength to meet the quality and purity characteristics which they purport to have." The expectation from FDA is that a recombinant vaccine shall be well-characterized in terms of its purity, identity, efficacy, potency, consistency, stability, and most importantly, its safety. The goal of a manufacturing process is to produce an adequate predetermined quantity of product at a predetermined level of quality (i.e., a product that meets rigorous acceptance criteria for purity, identity, efficacy, potency, consistency, stability, and safety). Because traditional biologic products (including vaccines) are prepared from biological sources that exhibit inherent biological variability, the ability of a manufacturer to prepare a safe product consistently and reproducibly is a concern. In-line processing data or in-process testing provide information that the manufacturing process is consistent and reproducible. If the process is consistent and reproducible, there is a high probability the product will be of the same high quality each time it is manufactured.

Much of our work over the past 4 years has been devoted to developing scaled-up manufacturing processes for each $\mathrm{H}_{\mathrm{C}}$ vaccine, and the in-process and lot release testing to validate the product's quality. Detail information on assay development and assay validation, genetic characterization of clones, in-process and lot release testing, product stability testing (e.g., real time, reconstituted, and accelerated stability), and formulation studies on the vaccine candidates was beyond the scope of this review and not provided. However, it should be realized that extensive testing must be performed on the products if the products are to be well-characterized and allowed into clinical trials.

\section{Acknowledgments}

The authors thank Terry Smith, Vickie Montgomery, and Matthew Hinz for performing potency, efficacy, and ELISA experiments. We thank Dr. Michael Meagher, Dr. Wenhui Zhang, Dr. Mark Bevins, Dr. Vijay Chiruvolu, and Dr. Karen Potter for their work on the fermentation optimization at the University of Nebraska-Lincoln, Biological Process Development Facility. We also thank Bonnie Loveless for providing technical assistance with expression vector constructs and pichia transformations.

\section{References}

[1] Lamanna C., The most poisonous poison, Science 130 (1959) 763-772.

[2] Habermann E., Dreyer F., Clostridial neurotoxins: handling and action at the cellular and molecular level, Cur. Top. Microbiol. Immunol. 129 (1986) 93-179.

[3] Schiavo G., Benfenati F., Poulain B., Rossetto O., Polverino P., de Laureto N., DasGupta B.R., Montecucco C., Tetanus and botulinum-B neurotoxins block neurotransmitter release by proteolytic cleavage of synaptobrevin, Nature 359 (1992) 832-835.

[4] Simpson L.L., Molecular pharmacology of botulinum toxin and tetanus toxin, Ann. Rev. Pharmacol. Toxicol. 26 (1986) 427-453.

[5] DasGupta B.R., Sugiyama H., A common subunit structure in clostridium botulinum type A, B, and E toxins, Biochem. Biophys. Res. Commun. 48 (1972) 108-112.

[6] DasGupta B.R., The structure of botulinum neurotoxins, in: Simpson L.L. (Ed.), Botulinum Neurotoxin and Tetanus Toxin, Academic Press, Inc., New York, 1989, pp. 53-67.

[7] Montecucco C., Schiavo G., Mechanism of action of tetanus and botulinum neurotoxins, Mol. Microbiol. 13 (1994) 1-8.

[8] Montecucco C., Papini E., Schiavo G., Bacterial protein toxins penetrate cells via a four-step mechanism, FEBS Lett. 346 (1994) 92-98.

[9] Halpern J.L., Neale E.A., Neurospecific binding, internalization, and retrograde axonal transport, in: Montecucco C. (Ed.), Current Topics in Microbiology and Immunology, Clostridial neurotoxins: the molecular pathogenesis of tetanus and botulism, Springer, Berlin, 1995, pp. 221-241.

[10] Black J.D., Dolly O., Interaction of ${ }^{125}$ I-botulinum neurotoxins with nerve terminals. I. Ultrastuctural autoradiographic localization and quantitation of distinct membrane acceptors for types A and B on motor nerves, J. Cell Biol. 103 (1986) 521-534.

[11] Nishiki T-I, Kamata Y., Nemoto Y., Omori A., Ito T., Takahashi M., Kozaki S., Identification of protein receptor for Clostridium botulinum type B neurotoxin in rat brain synaptosomes, J. Biol. Chem. 269 (1994) 10498-10503.

[12] Shone C.C., Hambleton P., Melling J., Inactivation of Clostridium botulinum type A neurotoxin by trypsin and purification of two tryptic fragments. Proteolytic action near the $\mathrm{COOH}$-terminus of the heavy subunit destroys toxin-binding activity, Eur. J. Biochem. 151 (1985) 75-82.

[13] Schengrund C.L., DasGupta B.R., Hughes C.A., Ringler N.J., Ganglioside-induced adherence of botulinum and tetanus neurotoxins to adducin, J. Neurochem. 66 (1996) 2556-2561.

[14] Nishiki T., Tokuyama Y., Kamata Y., Nemoto Y., Yoshida A., Sata K., Sekiguchi M., Takahashi M., Kozaki S., The high-affinity binding of Clostridium botulinum type B neurotoxin to synaptotagmin II associated with gangliosides $\mathrm{G}_{\mathrm{T} 1 \mathrm{~b}} / \mathrm{G}_{\mathrm{D} 1 \mathrm{a}}$, FEBS Lett. 378 (1996) 253-257.

[15] Li L., Singh B.R., Isolation of synaptotagmin as a receptor for types A and E botulinum neurotoxin and analysis of their comparative binding using a new microtiter plate assay, J. Nat. Toxins 7 (1998) 215-226.

[16] Middlebrook J.L., Cell surface receptors for protein toxins, in: Simpson L.L. (Ed.), Botulinum neurotoxins and tetanus toxin, Academic Press, Inc., New York, 1989, pp. 95-119.

[17] Shone C.C, Hambleton P., Melling J., A 50-kDa fragment from the $\mathrm{NH}_{2}$-terminus of the heavy subunit of Clostridium botulinum type A neurotoxin forms channels in lipid vesicles, Eur. J. Biochem. 167 (1987) 175-180.

[18] Black J.D., Dolly J.O., Interaction of ${ }^{125}$ I-labelled botulinum neurotoxins with nerve terminals. II. Autoradiographic evidence for its uptake into motor nerves by acceptor-mediated endocytosis, J. Cell. Biol. 103 (1986) 535-544. 
[19] Poulain B., Mochida S., Weller U., Högy B., Habermann E., Wadsworth J.D.F., Shone C.C., Dolly J.O., Tauc L., Heterologous combinations of heavy and light chains from botulinum neurotoxin A and tetanus toxin inhibit neurotransmitter release in Aplysia, J. Biol. Chem. 266 (1991) 9580-9585.

[20] Montal M.S., Blewitt R., Tomich J.M., Montal M., Identification of an ion channel-forming motif in the primary structure of tetanus and botulinum neurotoxins, FEBS Lett. 313 (1992) 12-18.

[21] Schmid M.F., Robinson J.P., DasGupta B.R., Direct visualization of botulinum neurotoxin-induced channels in phospholipid vessicles, Nature 364 (1993) 827-830.

[22] Lebeda F.J., Singh B.R., Membrane channel activity and translocation of botulinum and tetanus neurotoxins, J. Toxicol.-Toxin Revs. 18 (1999) 45-76.

[23] Oguma K., Fujinaga Y., Inoue K., Structure and function of Clostridium botulinum toxins, Microbiol. Immunol. 39 (1995) 161-168.

[24] Schiavo G., Rossetto O., Catsicas S., Polverino P., de Laureto N., DasGupta B.R., Benfenati F., Montecucco C., Identification of the nerve terminal targets of botulinum neurotoxin serotypes A, D, and E, J. Biol. Chem. 268 (1993) 23784-23787.

[25] Shone C.C., Quinn C.P., Wait R., Hallis B., Fooks S., Hambleton P., Proteolytic cleavage of synthetic fragments of vesicleassociated membrane protein, isoform- 2 by botulinum type B neurotoxin, Eur. J. Biochem. 217 (1993) 965-971.

[26] Schiavo G., Poulain B., Rossetto O., Benfenati F., Tauc L., Montecucco C., Tetanus toxin is a zinc protein and its inhibition of neurotransmitter release and protease activity depend on zinc, EMBO J. 11 (1992) 3577-3583.

[27] Blasi J., Chapman E.R., Link E., Binz T., Yamasaki S., DeCamilli P., Sudhof T.C., Niemann H., Jahn R., Botulinum neurotoxin A selectively cleaves the synaptic protein SNAP-25, Nature 365 (1993) 160-163.

[28] Schiavo G., Sabtucci A., DasGupta B.R., Mehta P.P., Jontes J., Benfenati F., Wilson M.C., Montecucco C., Botulinum neurotoxin serotypes A and E cleave SNAP-25 at distinct $\mathrm{COOH}$-terminal peptide bonds, FEBS Lett. 335 (1993) 99-103.

[29] Binz T., Blasi J., Yamasaki S., Baumeiste A., Link E., Sudhof T.C., Jahn R., Niemann H., Proteolysis of SNAP-25 by types E and A botulinal neurotoxins, J. Biol. Chem. 269 (1994) 1617-1620.

[30] Foran P., Lawrence G.W., Shone C.C., Foster K.A., Dolly J.O., Botulinum neurotoxin $\mathrm{C} 1$ cleaves both syntaxin and SNAP-25 in intact and permeabilized chromaffin cells: correlation with its blockade of catecholamine release, Biochemistry 35 (1996) 2630-2636.

[31] Niemann H., Blasi J., Jahn R., Clostridial neurotoxins: new tools for dissecting exocytosis, Trends Cell Biol. 4 (1994) 179-185.

[32] Blasi J., Chapman E.R., Yamaski S., Binz T., Niemann H., Jahn R., Botulinum neurotoxin $\mathrm{C} 1$ blocks neurotransmitter release by means of cleaving HPC1/syntaxin, EMBO J. 12 (1993) $4821-4828$.

[33] Anderson J.H., Lewis G.E., Clinical evaluation of botulinum toxoids, in: Lewis G.E. (Ed.), Biomedical Aspects of Botulism, Academic Press, New York, 1981, pp. 233-246.

[34] Ellis R.J., Immunobiologic agents and drugs available from the Centers for Disease Control. Descriptions, recommendations, adverse reactions, and serologic response, 3rd ed., Centers for Disease Control, Atlanta, GA, 1982.

[35] Fiock M.A., Cardella M.A., Gearinger N.F., Studies of immunities to toxins of Clostridium botulinum. IX. Immunologic response of man to purified pentavalent $\mathrm{ABCDE}$ botulinum toxoid, J. Immunol. 90 (1963) 697-702.

[36] Siegel L.S., Human immune response to botulinum pentavalent (ABCDE) toxoid determined by a neutralization test and by an enzyme-linked immunosorbent assay, J. Clin. Microbiol. 26 (1988) 2351-2356.

[37] Midura T.F., Nygaard G.S., Wood R.M., Bodily H.L., Clostridium botulinum type F: isolation from venison jerky, Appl. Microbiol. 24 (1972) 165-167.
[38] Green J., Spear H., Brinson R.R., Human botulism (type F)--a rare type, Am. J. Med. 75 (1983) 893-895.

[39] Sonnabend W.F., Sonnabend O.A., Grundler P., Ketz E., Intestinal toxicoinfection by Clostridium botulinum type F in an adult. Case associated with Guillain-Barre syndrome, Lancet 1 (1987) 357-361.

[40] Hatheway C.L., Toxoid of Clostridium botulinum type F: purification and immunogenicity studies, Appl. Environ. Microbiol. 31 (1976) 234-242.

[41] Montgomery V.A., Makuch R.S., Brown J.E., Hack D.C., The immunogenicity in humans of a botulinum type $F$ vaccine, Vaccine 18 (2000) 728-735.

[42] Atassi M.Z., Oshima M., Structure, activity, and immune (T and B cell) recognition of botulinum neurotoxins, Crit. Rev. Immunol. 19 (1999) 219-260.

[43] Atassi M.Z., Dolimbek B.Z., Hayakari M., Middlebrook J.L., Whitney B., Oshima M., Mapping of the antibody-binding regions on botulinum neurotoxin H-chain domain 855-1296 with antitoxin antibodies from three host species, J. Prot. Chem. 15 (1996) 691-700.

[44] Pushko P., Parker M., Ludwig G.V., Davis N.L., Johnston R.E., Smith J.F., Replicon-helper systems from attenuated Venezuelan equine encephalitis virus: Expression of heterologous genes in vitro and immunization against heterologous pathogens in vivo, Virology 239 (1997) 389-401.

[45] Helting T.B., Nau H.H., Analysis of the immune response to papain digestion products of tetanus toxin, Acta Pathol. Microbiol. Scand. Section C 92 (1984) 59-63.

[46] Fairweather N.F., Lyness V.A., Maskell D.J., Immunization of mice against tetanus with fragments of tetanus toxin synthesized in Escherichia coli, Infect. Immun. 55 (1987) 2541-2545.

[47] Smith L.A., Development of recombinant vaccines for botulinum neurotoxin, Toxicon 36 (1998) 1539-1548.

[48] Thompson D.E., Brehm J.K., Oultram J.D., Swinfield T.J., Shone C.C., Atkinson T., Melling J., Minton N.P., The complete amino acid sequence of the Clostridium botulinum type A neurotoxin, deduced by nucleotide sequence analysis of the encoding gene, Eur. J. Biochem. 189 (1990) 73-81.

[49] LaPenotiere H.F., Clayton M.A., Middlebrook J.L., Expression of a large, nontoxic fragment of botulinum neurotoxin serotype $A$ and its use as an immunogen, Toxicon 33 (1995) 1383-1386.

[50] Clayton M.A., Clayton J.M., Brown D.R., Middlebrook J.L., Protective vaccination with a recombinant fragment of Clostridium botulinum neurotoxin serotype A expressed from a synthetic gene in Escherichia coli, Infect. Immun. 63 (1995) 2738-2742.

[51] Dertzbaugh M.T., West M.W., Mapping of protective and crossreactive domains of the type A neurotoxin of Clostridium botulinum, Vaccine 14 (1996) 1538-1544.

[52] Kiyatkin N., Maksymowych A.B., Simpson L.L., Induction of an immune response by oral administration of recombinant botulinum toxin, Infec. Immun. 65 (1997) 4586-4591.

[53] Haggerty G.C., Development of tier 1 neurobehavioral testing capabilities for incorporation into pivotal rodent safety assessment studies, J. Amer. Coll. Toxicol. 8 (1989) 53-69.

[54] O'Donoghue J.L., Screening for neurotoxicity using a neurologically based examination and neuropathology, J. Am. Coll. Toxicol. 8 (1989) 97-116.

[55] Cregg J.M., Tschopp J.F., Stillman C., Siegel R., Akong M., Craig W.S., Buckholz R.G., Madden K.R., Kellaris P.A., Davis G.R., Smiley B.L., Cruze J., Torregrossa G., Velicelebi G., Thill G.P., High-level expression and efficient assembly of hepatitis B surface antigen in the methylotrophic yeast, Pichia pastoris, Bio/Technology 5 (1987) 479-485.

[56] Sreekrishna K., Potenz R.H.B., Cruze J.A., McCombie W.R., Parker K.A., Nelles L., Mazzaferro P.K., Holden K.A., Harrison R.G., Wood P.J., Phelps D.A., Hubbard C.E., Fuke M., High level expression of heterologous proteins in methylotrophic yeast Pichia pastoris, J. Bas. Microbiol. 28 (1988) 265-278. 
[57] Romanos M.A., Scorer C.A., Clare J.J., Foreign gene expression in yeast: a review, Yeast 8 (1992) 423-488.

[58] Cregg J.M., Vedvick T.S., Raschke W.C., Recent advances in the expression of foreign genes in Pichia pastoris, Biotechnology 11 (1993) 905-909.

[59] Clare J.J., Rayment F.B., Ballantine S.P., Sreekrishna K., Romanos M.A., High-level expression of tetanus toxin fragment $\mathrm{C}$ in Pichia pastoris strains containing multiple tandem integrations of the gene, Biotechnology 9 (1991) 455-460.

[60] Makoff A.J., Oxer M.D., Romanos M.A., Fairweather N.F., Ballantine S., Expression of tetanus toxin fragment $\mathrm{C}$ in E. coli: high level expression by removing rare codons, Nucleic Acids Res. 17 (1989) 10191-10202.

[61] Romanos M.A., Makoff A.J., Fairweather N.F., Beesley K.M., Slater D.E., Rayment F.B., Payne M.M., Clare J.J., Expression of tetanus toxin fragment $\mathrm{C}$ in yeast: gene synthesis is required to elimate fortuitous polyadenylation sites in AT-rich DNA, Nucleic Acids Res. 19 (1991) 1461-1467.

[62] Anderson S.G.E., Kurland C.G., Codon preferences in free-living microorganisms, Microbiol. Rev. 54 (1990) 198-210.

[63] Sreekrishna K., Strategies for optimizing protein expression and secretion I the methylotrophic yeast Pichia pastoris, in: Baltz R.H., Hegeman G.D., Skatrud P.L. (Eds.), Industrial Microorganisms: Basic and Applied Molecular Genetics, American Society for Microbiology, Washington, D. C., 1993, pp. 119-126.

[64] Umland T.C., Wingert L.M., Swaminathan S., Furey W.F., Schmidt J.J., Sax M., Structure of the receptor binding fragment $\mathrm{H}_{\mathrm{C}}$ of tetanus neurotoxin, Nat Struct Biol. 4 (1997) 788-792.

[65] Lacy D.B., Tepp W., Cohen A.C., DasGupta B.R., Stevens R., Crystal structure of botulinum neurotoxin type A and implications for toxicity, Nat. Struct. Biol. 5 (1998) 898-902.

[66] Lebeda F.J., Olson M.A., Predicting differential antigen-antibody contact regions based on solvent accessibility, J. Prot. Chem. 16 (1997) 607-618.

[67] Bavari S., Pless D.S., Torres E.R., Lebeda F.J., Olson M.A., Identifying the principal protective antigenic determinants of type A botulinum neurotoxin, Vaccine 16 (1998) 1850-1856.
[68] Scorer C.A., Clare J.J., McCombie W.R., Romanos M.A., Sreekrishna K., Rapid selection using G418 of high copy number transformants of Pichia pastoris for high-level foreign gene expression, Bio/Technology 12 (1994) 181-184.

[69] Byrne M.P., Holley J., Titball R., Smith L.A., Expression, purification and efficacy of a recombinant vaccine candidate against botulinum neurotoxin type F from Pichia pastoris, J. Prot. Expr. Purif. 18 (2000) 327-337.

[70] Cregg J.M., Barringer K.J., Hessler A.Y., Madden K.R., Pichia pastoris as a host system for transformations, Mol. Cell. Biol. 5 (1985) 3376-3385

[71] Potter K.J., Bevins M.A., Vassilieva E.V., Chiruvolu V.R., Smith T., Smith L.A., Meagher M.M., Production and purification of heavy chain fragment $\mathrm{C}$ of botulinum neurotoxin, serotype $\mathrm{B}$, expressed in the methylotropic yeast Pichia pastoris, J. Prot. Expr. Purif. 13 (1998) 357-365.

[72] Zhang W., Bevins M.A., Plantz B.A., Smith L.A., Meagher M.M., Modeling Pichia pastoris growth on methanol and optimizing the production of a recombinant protein, the heavy-chain fragment $\mathrm{C}$ of botulinum neurotoxin, serotype A, Biotechnol. Bioeng (2000) in press.

[73] Byrne M.P., Smith T.J., Montgomery V.A., Smith L.A., Purification, potency, and efficacy of the botulinum neurotoxin type A binding domain from Pichia pastoris as a recombinant vaccine candidate, Infect. Immun. 66 (1998) 4817-4822.

[74] Potter K.A., Zhang W., Smith L.A., Meagher M.M., Production and purification of the heavy chain fragment $\mathrm{C}$ of botulinum neurotoxin, serotype A, expressed in the methylotrophic yeast Pichia pastoris, Prot. Exp. Purif. (2000) in press.

[75] Boles J.W., West M.W., Montgomery V.A., Tammariello R.F., Smith L.A., Pitt M.L., Efficacy of recombinant C fragment of heavy chain botulinum neurotoxin serotype $\mathrm{B}$ against lethal aerosol challenge of botulinum $\mathrm{B}$ toxin in rhesus monkeys, The Toxicologist 54 (2000) 174 abstract 817A. 